\title{
The Georeferenced Digital Database for Sustainable Land Use Management in Namibia
}

\author{
Lisho C. Mundia \\ Department of Geo-spatial Sciences and Technology, Namibia University of Science and Technology, Namibia
}

Copyright $\bigcirc 2016$ by authors, all rights reserved. Authors agree that this article remains permanently open access under the terms of the Creative Commons Attribution License 4.0 International License

\begin{abstract}
The article presents the empirical findings on the georeferenced digital database for sustainable land use management of the Hardap region, Namibia. The research signifies the continuous value of geographical data management for land use planning and management in Namibia. The research applied a combination of approaches that include literature review, Geographical Information System (GIS), delineation of the imagery, Global Positioning Systems (GPS) and cartographic mapping. Both positive and negative impacts of the georeferenced digital database for sustainable land use management were explored. The research findings, among others, include the concepts, explanations, procedures and the value of the georeferenced digital database towards sustainable land use management. The research further provides important results such as existing organisational structures for spatial data management, elaborated procedures and steps for creating a georeferenced digital database for proper management of the GIS data in Namibia. Key recommendations include proper managed organisational structures for spatial data management, implementation of the elaborated procedures and steps for creating a georeferenced digital database for sustainable land use planning in Namibia.
\end{abstract}

Keywords Georeferenced, Digital, Database, Sustainable Land Use Management, Hardap Region, Namibia

\section{Introduction}

The main purpose of this paper is to share the concepts, explanations and procedures about the established georeferenced digital database that can be used as a model for sustainable land use planning in the Hardap region or any regional council. Geopublisher software was used for compiling the georeferenced digital database for storing and managing of raster and vector data, which was then customized to meet the requirements of the research objectives. In addition, the processes of compiling the georeferenced digital database were considered. This resulted in exploring the challenges and benefits associated with the georeferenced digital database in Namibia.

\section{The Study Area (Hardap Region)}

After Namibia's independence in 1990, the Hardap region was divided into six political constituencies: Gibeon, Mariental Rural, Mariental Urban, Rehoboth Rural, Rehoboth Urban East and Rehoboth Urban West (Government of Namibia [1]). In August 2013, the Hardap region was re-demarcated with two extra constituencies (Aranos and Daweb) by the President after the fourth Delimitation Commission's recommendation to bring about better service delivery to the community of the Hardap region. However, this study was done in the six original Hardap political constituencies. This is because the practical components (participatory mapping, participatory rural appraisal and focus group discussions) of the study were already done before the re-demarcation was implemented and there is still lack of data in the two new constituencies.

In terms of land, private farmers on a freehold basis own approximately $75 \%$ of the surface area of the Hardap region. The second largest landowner is the government that owns the extreme western part that constitutes approximately $15 \%$ of the area and is designated as part of the Namib-Naukluft Park. The central-southern part of the region is designated as communal farmland representing about $10 \%$ of the area over which traditional authorities and small-scale farmers hold control (Government of Namibia [1]).

Mendelsohn et al., [2] stressed that "other small parcels of land, scatted throughout the region, are owned by government, including about ten resettlement farms, two parcels dedicated to government agriculture and one additional protected area surrounding the Hardap Dam. Ten (10) designated local authorities are situated in different areas within Hardap Region with the largest being Rehoboth in the far north of the region and including the regional capital, Mariental located further in the south." 


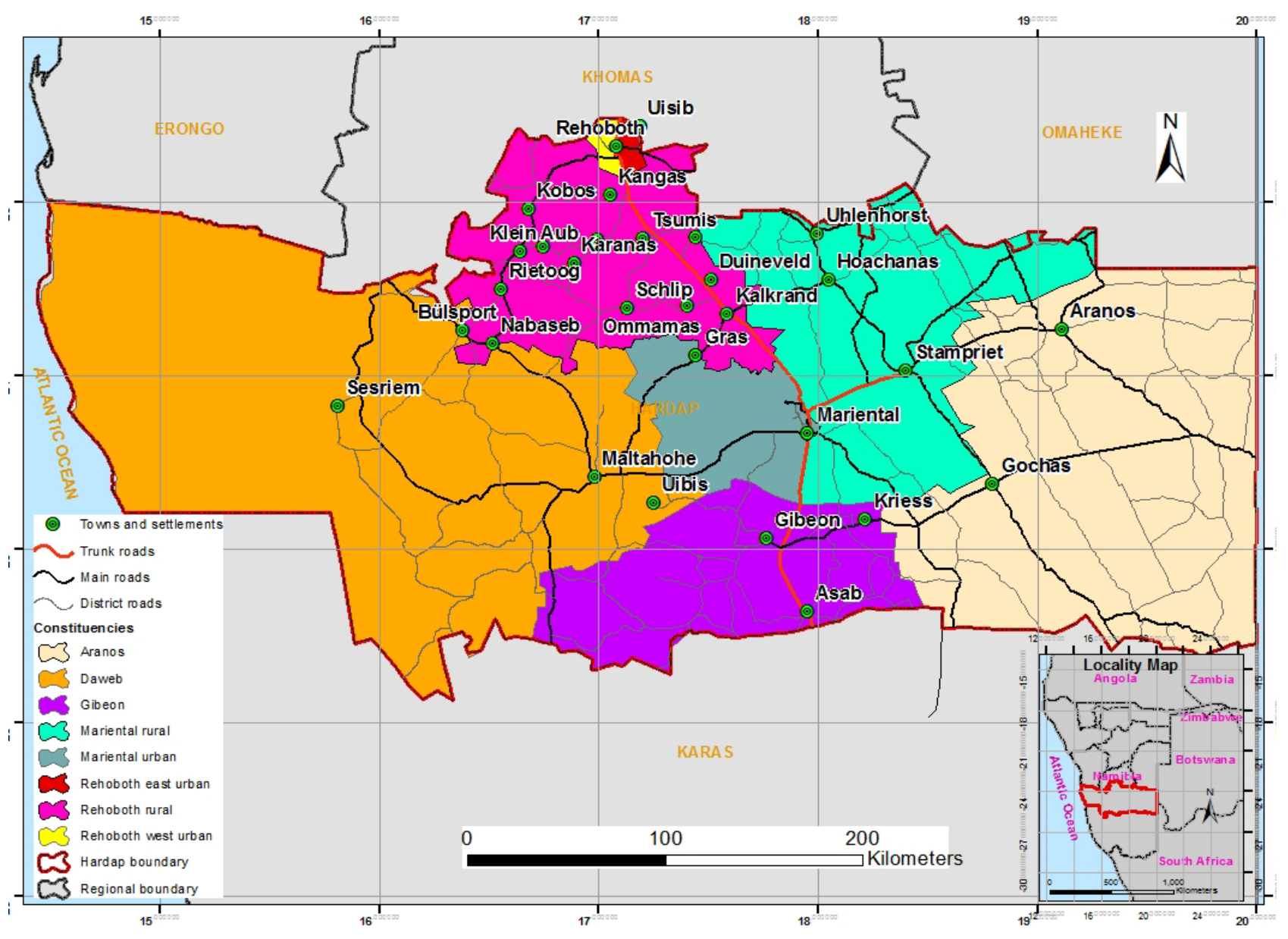

Figure 1. Study area

The study area is located in the south of Namibia, as seen on Figure 1. The Hardap region measures about 109000 $\mathrm{km}^{2}$ and the region has a population of approximately 79 000 people (Namibia Statistics Agency [3]). The region was chosen mainly due to a presence of a combination of issues that may easily lead to land disputes. These issues include, environmental issues, competitive industries who use the land for mining, agriculture and nature conservation, and an uneven distribution of infrastructure, such as boreholes, wind pumps and water canals. Flooding of the area has occurred when the sluice gates of Hardap Dam had to be opened to control dam water level. It is mainly the town of Mariental that has been affected by such flooding.

The participatory mapping aided by GIS for sustainable LUP was carried out in six different land portions as per constituencies of the Hardap region. The land portions where participatory mapping took place vary in land uses. Participatory mapping exercises were carried out at selected sites in each of the six constituencies of the Hardap region. These included rural, peri-urban and urban sites.

The use of the word 'Hardap' as the name of the region reflects the prominent role of the Hardap Dam in the agro-economic and tourism sectors of this region. The two major towns of the region are Rehoboth and Mariental.

\section{The Methodology Perspective}

There was a need to use GIS for creating land use maps from existing land use data of the Hardap region. Comparison of desired and undesired land uses was done with the participation from local, regional and national stakeholders. The use of GIS also contributed to help respond to the main research objective which is to produce a comprehensive user-friendly digital georeferenced database for integrated sustainable land use management in the Hardap region.

A database was created to store all collected spatial data and participatory maps. The spatial data, participatory maps and produced GIS maps were all stored in a digital georeferenced database which was developed using Geopublisher software. The software was also further used for storing of all participatory maps, storing raster and vector data which. The software was chosen to be used for spatial data management in this study because it was suitable for managing and monitoring different land use planning data and information.

The ArcGIS 10.x software was used for data analysis and cartographical mapping. It was chosen as it is compatible with most handheld GPS for downloading and uploading spatial data and it is widely available and commonly used in Namibia. Spatial data processing such as overlaying and 
other qualitative mapping processing and analyses was conducted using the ArcGIS 10.x software after verifying the land use categories with the local communities and line ministries. The land uses were delineated with the help of the land users in the local communities. Müller and Wode [4] state that "in this process villagers delineate their land use on transparencies laid over an orthophotograph." Semi-detailed sketch and photo-maps of these areas were prepared by the researcher at appropriate scales $(1: 25000$ to 1: 50 000), using ortho-photo and topographic mosaics as backdrop. The results of the delineation mapping were then overlaid on the digital raster imagery in the ArcGIS 10.x software. The results were then verified with the point data collected by means of a GPS and the existing secondary data for final analysis.

Spatial data processing was done using all the available spatial base data from secondary sources in the study area. As spatial base data did not meet all requirements about coordinates and attributes, the researcher, using handheld GPS instruments to supplement the existing spatial base data, also collected spatial data such as location of water points, public telephone points and telecommunication poles.

The researcher in the pre-preparation of the datasets edited other secondary data such as farm datasets, roads, water infrastructure, telecommunication infrastructure and towns' datasets. This was done in order to meet the integrated land use planning data standards as required in this study and in accordance with national spatial data standards of Namibia.

The line ministries, partner organizations such as non-governmental organizations and local authorities were the main sources of spatial data, such as ortho-photos, topographic maps, GIS vector data, and satellite images, and other information relevant to this study. These organizations and authorities are the data custodians, main ministries and organizations to which sustainable integrated land use planning is of vital concern in Namibia.

Further data descriptions and data values were captured as attributes for each land use dataset. These land use datasets were data such as the land sizes, the land ownership, the present land use, the potential future land use and the respective development potential or problems, risks or environmental hazards.

\section{Context on Georeferenced Digital Database for Land Use Planning}

Since 1995, significant steady progress has been made regarding management of spatial data in Namibia. However, there is room for improvement to enable GIS users in remote areas to access complete, secure and updated spatial data. As indicated by Noongo [5], "GIS have facilitated the production and generation of digital data in various government agencies tasked with planning, managing and monitoring of natural resources. In most cases data that are collected for a particular project are useful for other projects."

Noongo [5] stated that "much of the data in Namibia takes the form of maps and paper records. There has, nevertheless, been a realization that the use of computers in data management necessitates availability of such data in digital formats. Consequently, efforts are underway to create digital databases in many agencies through the conversion of existing maps and paper records into digital format. The current progress in database development shows that various agencies are implementing components of data infrastructure to better manage and utilize their datasets."

The government of Namibia formulated an ambitious vision which stipulates that, by 2030; Namibia should join the ranks of high-income countries and afford citizens an improved quality of life, comparable to that of the developed world (National Planning Commission (NPC) [6]). In Vision 2030, it is envisaged that rapid economic growth, accompanied by equitable social development, would result. The tools, which serve to drive national implementation programmes, are five-year National Development Plans (NDPs).

According to the NPC [6], "the main development objective of deploying GIS and statistics was to contribute to the development of a knowledge-based economy and technology-driven nation." This entails the enhancement of GIS and statistics managed by the Office of the President, under the NPC Secretariat. The specific objective was to improve production, accessibility and distribution of geospatial and statistical information. During the 2001 Census, GIS was used to create digital maps to facilitate the data-collection process (Mwazi [7]). The project - titled "GIS and Statistics Development in Namibia" was realized in August 2007 through a funding agreement between the Central Bureau of Statistics (CBS) in the NPC and the Development Cooperation of the Grand Duchy of Luxembourg.

A number of sub-projects were realized, including a Bachelor of Geo-Information Technology Degree offered at Namibia's University of Science and Technology, formally known as the Polytechnic of Namibia (PoN). The said course has already been implemented.

The development of GIS in Namibia together with the promotion of the use of official statistics at regional level is in line with the Vision 2030 goal, which is to create a knowledge-based economy. A commitment was undertaken by GRN to improve access to spatial information and statistics by the year 2011. The spatial information and statistics sub-sector of the NDPs is comprised of the two broad inter-related areas namely, spatial information and official statistics. Production of statistics and management are common to both spatial information and official statistics. Spatial, statistical and other attribute data are seen as providing the bedrock for e-government ${ }^{1}$.

1 E-Government is the use of information and communication technologies (ICTs) to improve the activities of public sector organizations. 


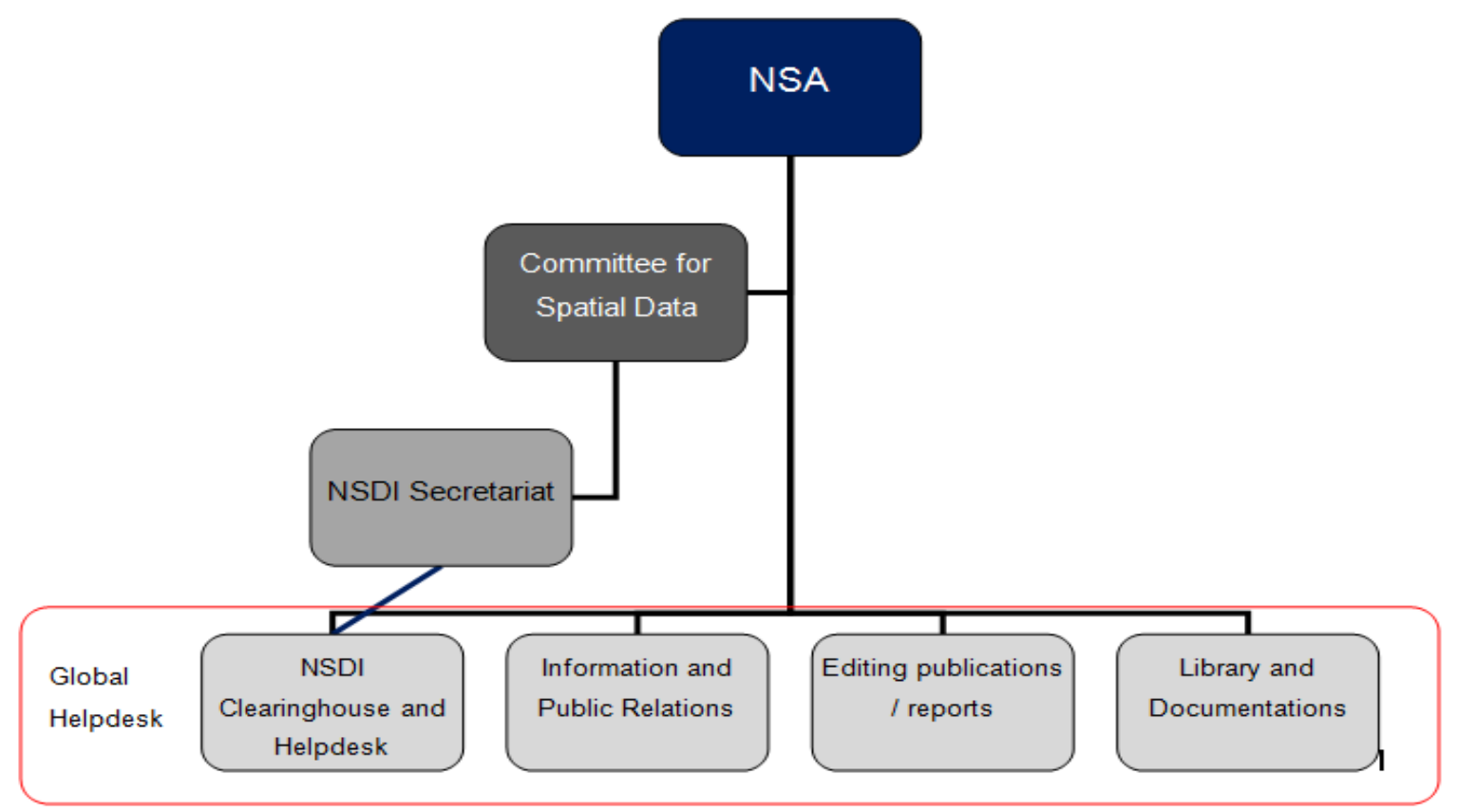

Source: Government of Namibia [9]

Figure 2. NSDI coordination structure

The NPC together with the MLR in Namibia has cooperated in formulating the National Spatial Data Infrastructure (NSDI) Policy. The Spatial Data Infrastructure (SDI) is a set of policies, standards and procedures under which organizations and technologies interact to foster use that is more efficient, management and production of spatial data. According to the Government of Namibia [8], "the purpose of this NSDI Policy for the Republic of Namibia is to set out a policy for the collection, processing, integrating, storing, distribution, and improved access and utilization of spatial data and services. The policy guides spatial data activities of public, private and civil society organizations in Namibia."

The Government of Namibia [8] maintains that the "NSDI provides the basis or structure of practices and relationships among data producers and users that facilitate data sharing and use. The goal of this infrastructure is to:

- develop and mainstream common understanding of SDI in Namibia;

- $\quad$ address the need for policies that promote NSDI;

- promote the use of available spatial data in Namibia;

- promote free access to spatial data within Government, free viewing of unrestricted public sector spatial data and free access to metadata;

- $\quad$ promote transparency of user conditions and restrictions;

- create a single point of access to available spatial data;

- $\quad$ reduce the duplication of effort among stakeholders;

- improve quality and reduce costs related to the production and usage of data;

- provide easy, efficient and equitable access to spatial data where technology, data formats, institutional arrangements, location, costs and conditions do not inhibit its use;

- $\quad$ promote the development of private value added services;

- $\quad$ preserve confidentiality, privacy, security and intellectual property rights, which will protect the rights of data custodians and all sectors of the community;

- $\quad$ establish partnerships between the Government, the private sector and academia to increase data availability and accessibility; and facilitate capacity building at individual, institutional and systemic levels (and through public and private partnerships)."

The institutional home of the NSDI is the Namibia Statistics Agency (NSA) - previously known as the Central Bureau of Statistics (CBS) - , which is fully developed as a stated agency. The NSA functions under the new Statistics Act of 2011, which provides for its functioning. It also includes the functions of the NSDI into this act. The Government of Namibia [9] maintains that "NSA is tasked to coordinate NSDI within the Government." The NSDI coordination structure is depicted in Figure 2.

The Government of Namibia [9] pointed out that "the Committee for Spatial Data is established as the advisory body for the Agency and is therefore an important coordinating mechanism for all NSDI activities in Namibia. Besides an advisory role, it must:

- facilitate, promote and safeguard an environment for the efficient collection, management, distribution and utilization of spatial data;

- promote awareness of its activities, including dissemination of information on the importance of 
spatial data for effective governance, planning and decision-making;

- be consulted before any spatial data are captured unless a national emergency makes such prior consultation impossible or impractical; and

- before the Agency makes any standard relating to the NSDI or formulate the NSDI policy the Agency must consult the committee for Spatial Data."

The committee for spatial data comprises of members from the government, academia, the public and private sectors and NGOs. At the same time, the NSDI Secretariat, the NSA to support the committee and implement approved recommendations (Government of Namibia [9]) will establish including the NSDI Clearinghouse and Helpdesk.

\section{The Results Perspectives}

De By, Georgiadou, Knippers, Kraak, Sun, Weir and van Westen [10] stated that "large computerized collections of structured data are what we call a database." A database management system (DBMS) is a software package that allows the user to set up, use and maintain a database. Like a GIS allows setting up a GIS application, a DBMS offers generic functionality for database organization and data handling (De By et. al., [10]). The established georeferenced digital database provides custom, flexible and dedicated data management functionalities to decision-makers and in this particular case, people and institutions responsible for land use planning. The georeferenced digital database was designed for:

- providing timely, transparent and easily readable outputs;

- $\quad$ streamlining the production of maps, thus reducing time and cost requirements; and

- transforming data and information into knowledge.

The process of designing a georeferenced digital database included a number of steps as illustrated in Figure 3. The database design was composed into six steps. The steps are a continuation of activities from stage 1 to stage 6 , but are not necessarily strictly sequential. The entire process makes provision for feedback which means that the researcher can still revisit earlier stages during a later stage.

Dobesova [11] stated that "Geographical Information Systems (GIS) maps are prepared in GIS software and based on data stored in a database. During the conceptual database design stage, the graphic editor of a database model is recommended." The conceptual database modelling stage was the second phases of the georeferenced digital database design. The process of designing the georeferenced digital database in steps is very useful as it contributes to enhance the understanding of the database for the administrator and users. The phases of the database design were applied during the identification of the key data layers, data structures, as well as refining and compiling documentation describing the database model. The georeferenced digital database designing steps are further explained in Table 1.

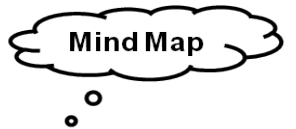

Independent - DBMS

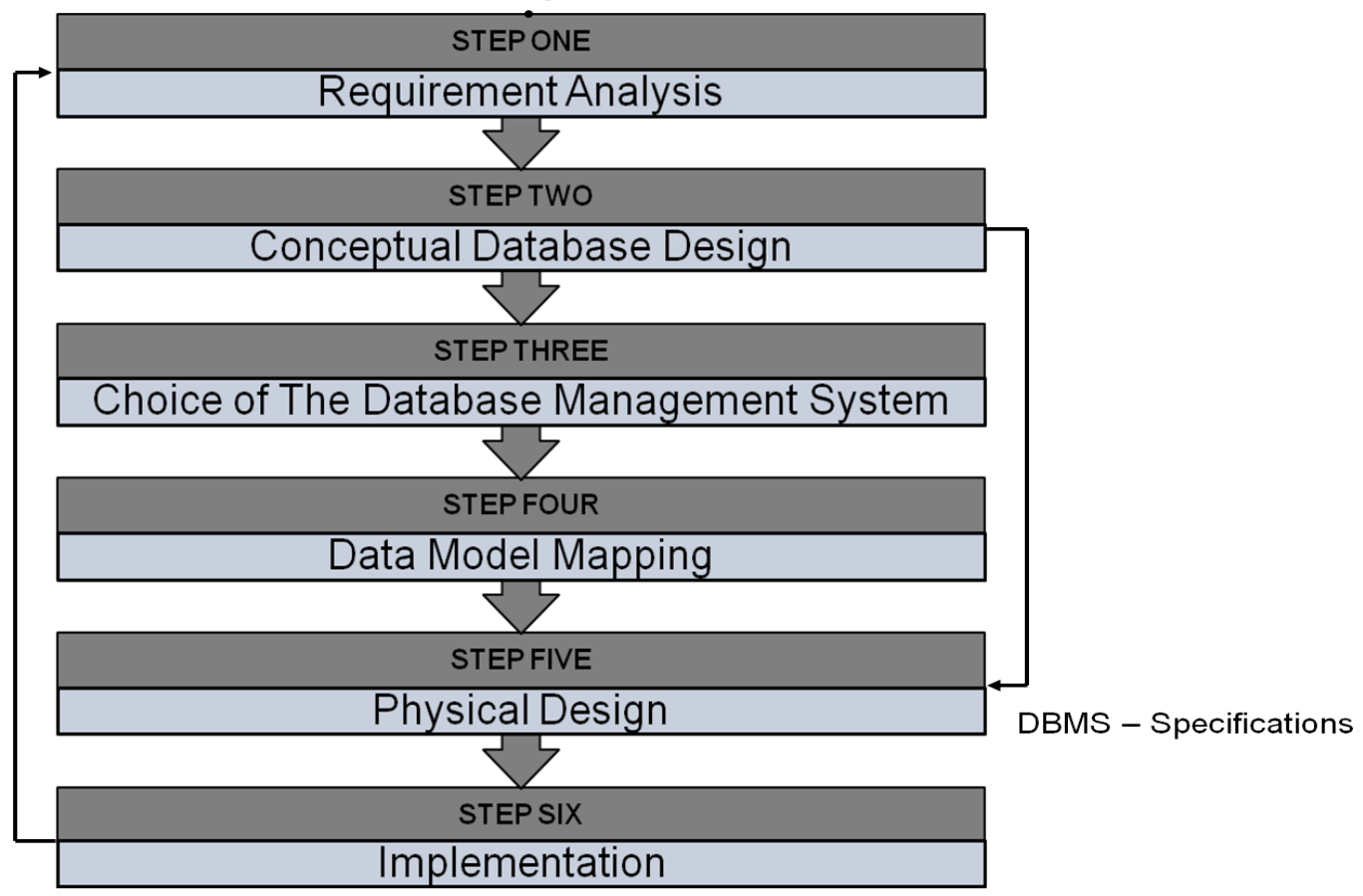

Source: Adapted from: De By et al., [10]

Figure 3. Steps undertaken in the design of a georeferenced digital database 
Before starting with the process a mind map needs to be drawn up. This is the step where the researcher starts identifying the need, purpose and importance of the georeferenced digital database in the land use planning process. Once the need, purpose and importance were identified, Step 1, Analysis of requirements, is undertaken, followed by the design of the conceptual database, choice of the database management system (DBMS), data model conceptualization, physical design and eventually the implementation. The purpose of each step and activities to be carried out during the respective stages are provided in Table 1.

The georeferenced digital database that was developed allows many customized functionalities such as storing, viewing, querying, maintaining and manipulation of data. The database has customized metadata describing the state and condition of the data. The metadata included the descriptions of layer titles and the shape of the layers to continue improving the availability of spatial data documentation in Namibia. Metadata will help the Ministry of Land and Resettlement and other stakeholders to infer the necessary descriptive information, such as content, quality, condition and currency.

The georeferenced digital database has been customized to the Namibia projection system standard. The projection and geographical coordinate system was adopted for the Hardap region's georeferenced digital database system because it is a Namibia-based system. Table 2 shows the projection system parameters. The data imported into the georeferenced digital database will automatically change the general projection into the Namibian projection and geographical system standard.

Table 1. Steps and explanations in designing the georeferenced digital geo-database

\begin{tabular}{|c|c|c|}
\hline No. & Steps & Purpose and activities \\
\hline 0. & Mind map & The need for and importance of the georeferenced digital database were identified during this stage. \\
\hline 1. & Analysis of requirements & $\begin{array}{l}\text { The main purpose of this stage was to document the data requirements of the users such as MLR and } \\
\text { other relevant stakeholders. The typical activities were: } \\
\text { Identification of application areas and user groups. } \\
\text { Analyses of existing documentation of relevant policy documents, forms and reports. } \\
\text { Analyses of current operating environments and the intended use of the information. }\end{array}$ \\
\hline 2. & Design of conceptual database & $\begin{array}{l}\text { During this stage, the data types of the database were examined, resulting from the data requirements } \\
\text { analysis set in Stage } 1 .\end{array}$ \\
\hline 3. & $\begin{array}{l}\text { Choice of the database } \\
\text { management system (DBMS) }\end{array}$ & $\begin{array}{l}\text { The best deployment platform for implementing the produced schema was established. The activities } \\
\text { were to identify the: } \\
\text { type of database management system (for example relational, network, deductive or object oriented). } \\
\text { user and program interfaces. } \\
\text { types of query languages. }\end{array}$ \\
\hline 4. & Data model mapping & $\begin{array}{l}\text { During this stage, the transformation of the generic DBMS conceptual schema into the data model of } \\
\text { the chosen DBMS was done. }\end{array}$ \\
\hline 5. & Physical design & $\begin{array}{l}\text { The main purpose was to choose the specific storage structures and access paths for the database files. } \\
\text { The activity included database testing before it was released for use. }\end{array}$ \\
\hline 6. & Implementation & $\begin{array}{l}\text { The implementation of the database application programs and the database operation were the main } \\
\text { purposes. The activities included that of maintaining the database and continuity of populating GIS } \\
\text { data into the database. }\end{array}$ \\
\hline
\end{tabular}

Table 2. Projection system parameters of Namibia

\begin{tabular}{|c|c|}
\hline Projection type & Transverse Mercator \\
\hline Projected coordinate system & Transverse Mercator \\
\hline Geographical coordinate system & GCS WGS 1984 \\
\hline Datum & WGS 1984 \\
\hline False easting & 600000.000000 \\
\hline False northing & 10000000.0000000 \\
\hline Central meridian & 17.000000 \\
\hline Scale factor & 1.000000 \\
\hline Latitude of origin & 0.000000 \\
\hline Linear unit & Meter (1.000000) \\
\hline Scale & Local, Regional and National \\
\hline
\end{tabular}


The georeferenced digital database of the Hardap region has a numerous layers. Some of the main layers are thematic themes, which include administration, natural environment, socio-economics and topography.

The database is one of the main outputs of this study. The research objective of the study namely to conceptualize and set up a user-friendly comprehensive georeferenced digital database was attained by developing the georeferenced digital database. The database can be used as a model by the MLR for sustainable land use planning in the region.
The georeferenced digital database contains layers of graphic information and their relational databases that are transformed into maps. The information allows the user to view a composite of a specific area, adding an array of graphically oriented decision-making tools to the land use planning process. The interface of the georeferenced digital database system is depicted in Figure 4. The extracted thematic map of the Hardap region's land ownership is depicted in Figure 5.

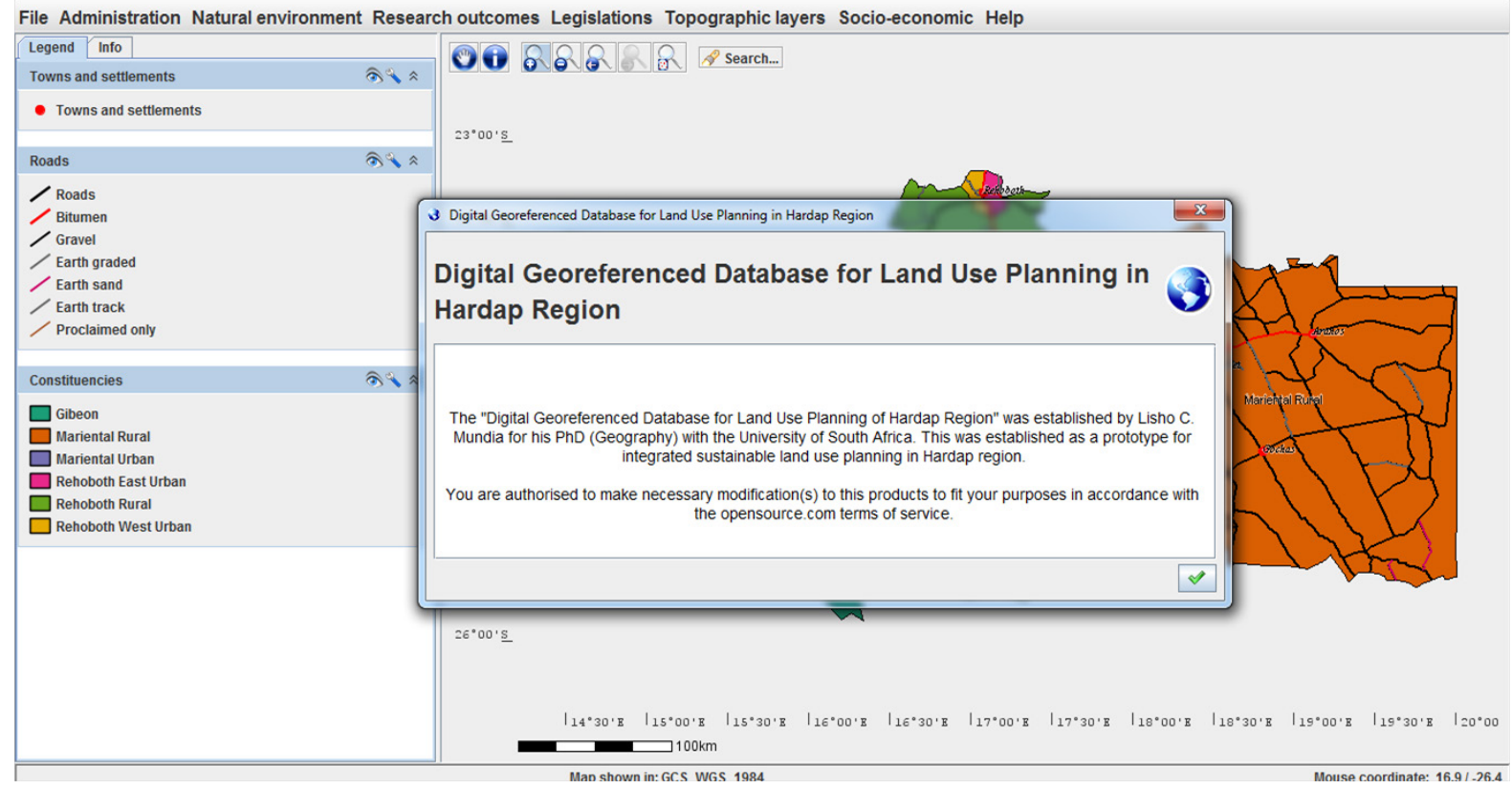

Figure 4. The interface of the georeferenced digital database

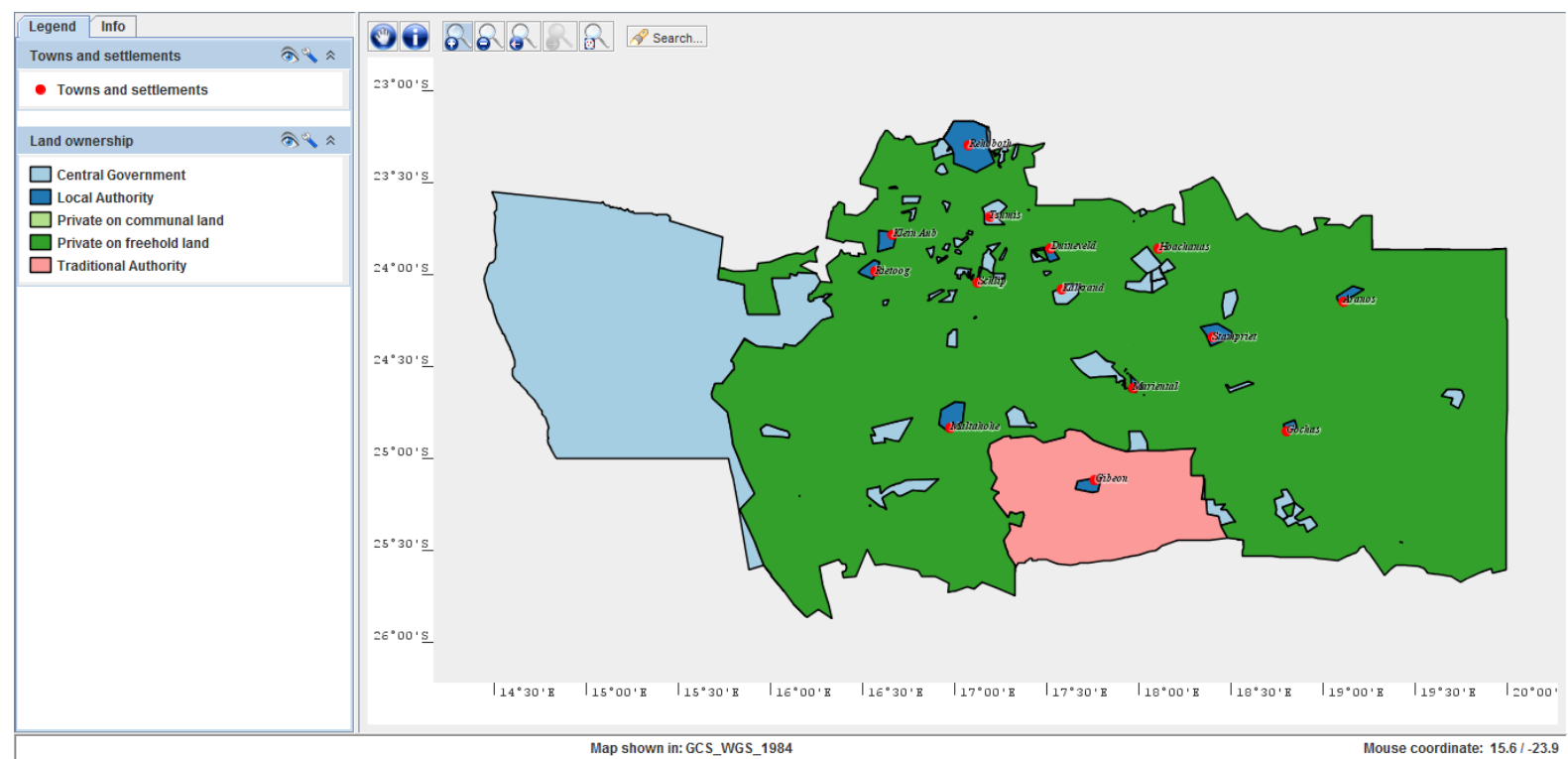

Figure 5. Screen shot of a thematic map of the land ownership of the Hardap region created from the georeferenced digital database 
A Geographical Information System (GIS) was used in this study for storing, managing, processing, manipulating and presenting spatial data. A GIS was also used for exploring large datasets for multi-purpose within the land use planning (Bae et al., [12]). The georeferenced digital database have substantial advantages over the traditional manual filing cabinet approach, such as transparency of decisions, a homogenous approach, quick response, responsive reaction to dynamic situations, ability to simulate scenarios and capacity to handle large amounts of data. The contribution of the georeferenced digital database can be viewed in the following three ways:

- The database: A database tool of the ILUP that offer an organized mechanism for storing, managing and retrieving land use information.

- The maps: A set of land use maps and natural resources maps that show features on the earth's surface. Maps of the geographical information can be constructed and used as windows of the database to support queries, analysis and editing of the information.

- The model: A model show abstraction of reality used to represent geographical features; examples are vector or raster data models processed in GIS software. The model contains sets of rules and procedures for representing a phenomenon or predicting an outcome.

Specific contributions that the georeferenced digital database has in this study are:

- managing and maintaining the spatial and non-spatial data;

- $\quad$ storing and managing participatory mapping result into the GIS database;

- $\quad$ processing of spatial and non-spatial data; and

- compiling of land use planning maps.

\section{Concluding Remarks}

The major objective of the study was to explain and explore the value and procedures used in the development of the georeferenced digital database for sustainable land use planning of the Hardap region. The georeferenced digital database is used to store and manage the existing spatial data and non-spatial data. The georeferenced digital database incorporated the outputs of study which are the participatory land use maps and GIS land use maps.

The research question on the frameworks and guidelines suggested for land use planning using participatory mapping aided by GIS to be implemented to ensure sustainable land management in Namibia was validated. This is because the study results show that a georeferenced digital database is an important tool in managing not only spatial data, but also non-spatial data and imagery data.

\section{Acknowledgements}

I am very grateful to the Namibia University of Science and Technology for the sabbatical leave. It allowed me sufficient time to complete this paper.

\section{REFERENCES}

[1] Government of Namibia. Regional poverty profile: based on village-level participatory poverty assessment in Hardap region. Windhoek: National Planning Commission, 2006b.

[2] Mendelsohn, J., Jarvis, A., Roberts, C. and Robertson, T. Atlas of Namibia: a portrait of the land and its people. Windhoek: Ministry of Environment and Tourism, 2002.

[3] Namibia Statistics Agency. Namibia 2011 Population and housing census basic report. Windhoek: Namibia Statistics Agency, 2013.

[4] Müller, D. and Wode, B. Manual on participatory village mapping using photomaps. Social Forestry Development Project (SFDP) Song Da. Son La, 2003.

[5] Noongo, E. N. The orientation of data access and accessibility in Namibia, Online available from http://geoinfo.uneca.org/s diafrica/country\%20information/namibia/nsdi\%20namibia $\%$ 20status1.doc

[6] National Planning Commission (NPC). Project documents GIS and statistics development in Namibia. National planning commission, Windhoek, Namibia, 2008.

[7] Mwazi, O. Geocoding and census mapping with GIS in Namibia, Central Bureau of Statistics, Online available from http://unstats.un.org/unsd/demographic/meetings/egm/Censu sMappingEGM07/docs/PPT/Namibia.ppt

[8] Government of Namibia. National Spatial Data Infrastructure (NSDI) policy for the Republic of Namibia. National Planning Commission, 2009.

[9] Government of Namibia. National spatial data infrastructure The role of the Namibia Statistics Agency, the committee for Spatial Data and terms of reference for the NSDI secretariat and helpdesk. National Planning Commission, 2011.

[10] De By, R.A., Georgiadou, P. Y., Knippers, R. A., Kraak, M. J., Sun, Y., Weir, M.J.C. and van Westen, C. J. Principles of geographic information systems: an introductory textbook. Enschede, ITC. ITC Educational Textbook Series 1, 2004.

[11] Dobesova, Z. Database modelling in cartography for the "Atlas of Election". Geodesy and cartography. Czech Republic: Taylor \& Francis Group. Vol. 38 (1) 20-26.

[12] Bae, W. D., Alkobaisi, S., and Leutenegger, S.T. IRSJ: Incremental refining spatial joins for interactive queries in GIS. Geoinformatica Vol. 14:507-543. 